\title{
Clinical analysis of HPV58-positive cervical cancer
}

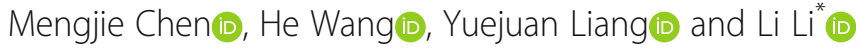

\begin{abstract}
Objective: To study the clinical features of HPV58-positive cervical cancer.

Methods: A retrospective analysis of 347 patients with HPV58- or HPV16 positive cervical cancer from the Department of Gynecology Tumor of Guangxi Medical University Affiliated Cancer Hospital was performed. Molecular hybridization was used to detect HPV genotypes. The clinical features, including age, pathology, and invasion, were compared between the HPV58 positive and HPV16 positive cervical cancer groups.

Results: A total of 347 patients were eligible for this study, and the proportion of patients who were with poorly differentiated cancer $(P=0.015)$ was significantly higher in the HPV58 positive group. HPV58 positivity was an independent risk factor for poorly differentiated cancer [HR 2.156, 95\% confidence interval: 1.167-3.984, $P=0.014$ ]. The percentage of uterus corps invasion is significantly lower in HPV58 $(p=0.041)$, but HPV58 positivity is the independent risk factor for uterus corps invasion [HR $=3.985,95 \%$ confidence interval: 1.066-14.893, $P=0.040]$. The overall survival of HPV58-positive cervical cancer patients with uterine corpus invasion was significantly lower $(P=$ 0.000). The age of patients in the HPV58-positive cervical cancer at advanced stage was significantly older ( $P=$ 0.045).

Conclusions: HPV58-positive cervical cancer patients are at higher risk of poorly differentiated cancer and uterus corps invasion. The patients with HPV58 positive cervical cancer with uterus corps invasion may result a worse prognosis.
\end{abstract}

Keywords: Human papilloma virus, Cervical cancer, Uterine corpus invasion, Prognosis

In the year 2015, there were 98,900 new cases of cervical cancer and 30,500 died [1]. High-risk human papilloma virus (HPV) subtypes play an important role in cervical cancer occurrence [2]. The most common high-risk HPV subtypes include the HPV16, 18, 58, 33, 45, 31, 52, 35, 59, 39, 51 and 56 [3]. In southwest China, the most common HPV genotype is HPV16 (54.67\% of cases), followed by HPV58 (13.33\% of cases) and HPV33 (5.33\%) [4]. In the Zhejiang Province of China, HPV16 (62.1\% of cases), HPV58 (10.52\% of cases), HPV18 (10.95\% of cases) and HPV52 (7.96\%) are predominant [5]. Similarly, in the

\footnotetext{
* Correspondence: gxilili0808@sina.com

Mengjie Chen and He Wang are co-first author

Guangxi Medical University affiliated Cancer Hospital, NO.71 Hedi Road

Qingxiu Square, Nanning City, Guangxi Province, China
}

Yangtze River basin, HPV16 is the most common subtype (65.77\% of cases), and the second most common is HPV58 (9.01\% of cases) [6]. HPV genotypes are regionally distributed. In general, HPV16, HPV18, and HPV58 are dominant in China [3, 7]. In addition, the rate of infection with HPV58 is significantly higher in Asia than in America, Africa and Australia [8]. More than $80 \%$ of cervical cancer cases have one or more of the HPV genotypes, including the $\alpha$-PV9 viruses (HPV16, 31, 33, 35, 52, 58 and 67) and the $\alpha$-PV7 viruses (HPV18, 39, 45, 59,68 and 70) [9].

Because of the specificity of HPV58, the high infection rate in Asia and the lack of intensive research, this study discusses the clinical features of HPV58-positive cervical cancer to provide references for diagnosis and prognostication. 


\section{Method}

\section{Clinical data}

A retrospective analysis of 347 patients with cervical cancer admitted in Department of Gynecology Oncology of Guangxi Medical University affiliated Cancer Hospital during 2010 to 2017 was performed. The patients were restaged according to the 2018 International Federation of Obstetrics and Gynecology (FIGO) staging system. Cases with metastatic cervical tumors, cervical cancer recurrence or with other existing malignant tumors were excluded. The research group was HPV58-positive cervical cancer, and the control group was HPV16 positive cervical cancer. Follow-up was performed by telephone. The patients with complete clinical data and follow-up data were eligible for the study. Patients who were lost to follow-up were excluded. The method used to categorize HPV genotypes was molecular hybridization.

\section{Administered therapy}

All eligible patients had finished treatment. The treatment plans were made according to National Comprehensive Cancer Network (NCCN) guidelines (Table 1).

\section{The evaluation of tumor invasion and metastasis}

For patients who received surgery, tumor invasion and metastasis were evaluated by postoperative pathology reports and preoperative CT or MRI reports. For patients who did not undergo surgery, tumor invasion and metastasis were evaluated by pretreatment CT or MRI.

\section{Statistical analysis}

Statistical analyses were performed using SPSS statistical software 22.0. Statistical descriptions were expressed as the mean \pm standard deviation. Chi-square tests or Fisher's test was used to calculate the differences between the data, and Student's t-test or group rank sum tests were used to grade the data. The Kaplan-Meier method was used to construct a survival curve, and the statistical significance between the curves was assessed with the log-rank test for univariate analysis. Binary logistic regression models were used for multivariate analysis. All statistical analyses were two-tailed, and a P-value less than 0.05 was considered statistically significant. The survival curve pictures were made by PRISM software 8.0 .

\section{Result \\ The clinical features of 347 patients with cervical cancer Clinical features}

A total of 347 patients with cervical cancer were included in the study, Of these, 79 patients had HPV58positive cervical cancer, a total of 74 cases were diagnosed with squamous cells carcinoma, 3 cases of adenocarcinoma and 2 cases of adenosquamous carcinoma. While 268 patients had HPV16 positive cervical cancer, including 256 cases of squamous cells carcinoma, 8 cases of adenocarcinoma and 4 cases of adenosquamous carcinoma (Table 2). The minimum age was 24 years old, the maximum age was 78 years old, and the median age was 52 years old. There were 63 cases and 176 cases of poorly differentiated cancer in the HPV58positive and HPV16 positive cervical cancer groups, respectively, accounting for $79.75 \%$ and $65.67 \%$ of cases. The proportion of poorly differentiated carcinoma was significantly higher in HPV58-positive cervical cancer than in the HPV16 positive group (Table 3).

\section{Risk factors for poorly differentiated cancer occurrence}

Univariate analysis was performed to explore the risk factors associated with poorly differentiated cancer occurrence. The result showed that HPV58 positivity was an independent risk factor for poorly differentiated cancer occurrence [HR 2.156, 95\% confidence interval: 1.167-3.984, $P=0.014]$. Additionally, squamous cells carcinoma was an independent risk factor for poorly differentiated cancer too, its risk for poorly differentiated cancer was 3.667 times than non-squamous cells carcinoma [HR 3.667, 95\% confidence interval: 1.335-10.130, $P=0.012]$. Other factors were not included in the multiple logistics analysis (Table 4).

Further analysis about the pathology type of squamous cells carcinoma was performed, the squamous cells carcinoma cases with HPV58 positivity was associated with increased risk for poorly differentiated cancer [HR7.038, 95\% confidence interval: 1.067-46.437, $P=0.043$ ]. However, the HPV16 positive squamous cells carcinoma cases did not show increased risk for poorly

Table 1 Administration

\begin{tabular}{|c|c|c|}
\hline Stage & Administered therapy & Adjunctive therapy \\
\hline IA & $\begin{array}{l}\text { Cone biopsy } \pm \text { extrafascial hysterectomy, or radical hysterectomy } \\
\text { +pelvic lymph node dissection } \pm \text { para-aortic lymph node dissection }\end{array}$ & \multirow{4}{*}{$\begin{array}{l}\text { If postoperative pathology showed the presence of risk factors, } \\
\text { adjunctive therapy was applied. Risk factors included: positive } \\
\text { lymph nodes, positive surgical margins, parametrial invasion, } \\
\text { tumor diameters over } 4 \mathrm{~cm} \text {, lymphovascular space invasion and } \\
\text { deep interstitial invasion }\end{array}$} \\
\hline $\mathrm{IB}$ & $\begin{array}{l}\text { Radical hysterectomy +pelvic lymph node dissection } \pm \text { para-aortic } \\
\text { lymph node dissection }\end{array}$ & \\
\hline$\| A$ & $\begin{array}{l}\text { Radical hysterectomy +pelvic lymph node dissection } \pm \text { para-aortic } \\
\text { lymph node dissection }\end{array}$ & \\
\hline IIB-IVB & Pelvic external beam radiotherapy \pm concurrent chemotherapy & \\
\hline
\end{tabular}


Table 2 HPV types and stages by hispathologytypes

\begin{tabular}{|c|c|c|c|c|c|c|}
\hline & \multicolumn{2}{|l|}{ SCC } & \multicolumn{2}{|c|}{ ADC/ASC } & \multicolumn{2}{|c|}{ Total } \\
\hline & $\bar{N}$ & $\%$ & $\bar{N}$ & $\%$ & $\bar{N}$ & $\%$ \\
\hline HPV58 & 74 & 93.67 & 5 & 6.34 & 79 & 22.77 \\
\hline HPV16 & 256 & 95.52 & 12 & 4.48 & 268 & 77.23 \\
\hline \multicolumn{7}{|l|}{ Stage } \\
\hline $\mid \mathrm{A} 1$ & 12 & 92.31 & 1 & 7.69 & 13 & 3.75 \\
\hline IA2 & 2 & 100 & 0 & 0 & 2 & 0.58 \\
\hline |B1 & 28 & 90.32 & 3 & 9.68 & 31 & 8.93 \\
\hline IB2 & 28 & 96.55 & 1 & 3.45 & 29 & 8.36 \\
\hline IB3 & 36 & 100 & 0 & 0 & 36 & 10.37 \\
\hline$\| \mathrm{A} 1$ & 20 & 100 & 0 & 0 & 20 & 5.76 \\
\hline$\| A 2$ & 35 & 94.59 & 2 & 5.41 & 37 & 10.66 \\
\hline$\| B$ & 50 & 90.91 & 5 & 9.09 & 55 & 15.85 \\
\hline$\| \mathrm{A}$ & 4 & 100 & 0 & 0 & 4 & 1.15 \\
\hline$\| \mathrm{II}$ & 48 & 96.00 & 2 & 4 & 50 & 14.41 \\
\hline IIIC1r & 38 & 97.44 & 1 & 2.56 & 39 & 11.24 \\
\hline IIIC2r & 10 & 100 & 0 & 0 & 10 & 2.88 \\
\hline IVA & 12 & 85.71 & 2 & 14.29 & 14 & 4.03 \\
\hline IVB & 7 & 100 & 0 & 0 & 7 & 2.02 \\
\hline
\end{tabular}

differentiated cancer [HR 0.335, 95\% confidence interval: 0.109-1.152, $P=0.085$ ] (Table 5).

\section{Survival analysis of HPV58- and HPV16 positive poorly differentiated cancers}

Overall survival was not significantly different between the HPV58- and HPV16 positive poorly differentiated cancer groups $(63.44 \pm 4.50$ months vs $57.21 \pm 1.93$ months, $P=0.775$ ) (Fig. 1).

\section{Analysis of stage IA-IIA cervical cancer}

Clinical features of stage IA-IIA cervical cancer patients

A total of 189 patients with stage II-IIA cervical cancer received surgery. The patients with HPV58-positive cervical cancer with uterine corpus invasion were significantly less than the HPV16 positive patients , accounting for $7.89 \%$ and $31.30 \%$ respectively $(p=0.041)$ (Table 6$)$.

\section{Comparison of overall survival in patients with and without} uterine corpus invasion

Among patients with stage IA-IIA cervical cancer, despite the HPV genotype, overall survival was significantly lower in patients with uterine corpus invasion than in patients without uterine corpus invasion $(49.27 \pm 2.72$ months vs $72.46 \pm 1.78$ months, $P=0.041$ ) (Fig. 2). Further analysis of the data revealed that the overall survival of HPV58-positive cervical cancer patients with uterine corpus invasion was significantly lower than that of without uterine corpus invasion (24.33 months vs
Table 3 The clinical feature of 347 patients with cervical cancer

\begin{tabular}{|c|c|c|c|c|}
\hline & HPV58 & HPV16 & Z & $P$ \\
\hline$\overline{\text { Age }}$ & & & 3.205 & 0.073 \\
\hline$\leq 50$ years old & 27 & 122 & & \\
\hline$>50$ years old & 52 & 146 & & \\
\hline Pathology type & & & 0.449 & 0.503 \\
\hline SCC & 74 & 256 & & \\
\hline Non-SCC & 5 & 12 & & \\
\hline Differentiation & & & 5.639 & 0.018 \\
\hline Poor & 63 & 176 & & \\
\hline Moderately/well & 16 & 92 & & \\
\hline Maximum diameter & & & 0.311 & 0.577 \\
\hline$<4 \mathrm{~cm}$ & 28 & 86 & & \\
\hline$\geq 4 \mathrm{~cm}$ & 51 & 182 & & \\
\hline Lymph node metastasis & & & 0.059 & 0.808 \\
\hline Yes & 28 & 99 & & \\
\hline No & 51 & 169 & & \\
\hline Bladder invasion & & & 0.169 & 0.681 \\
\hline Yes & 7 & 28 & & \\
\hline No & 72 & 240 & & \\
\hline Rectal invasion & & & 1.324 & 0.250 \\
\hline Yes & 3 & 20 & & \\
\hline No & 76 & 248 & & \\
\hline Vaginal invasion & & & 0.103 & 0.748 \\
\hline Yes & 25 & 90 & & \\
\hline No & 54 & 178 & & \\
\hline Uterine corpus invasion & & & 0.351 & 0.553 \\
\hline Yes & 57 & 84 & & \\
\hline No & 22 & 184 & & \\
\hline Distant metastasis & & & 0.014 & 0.906 \\
\hline Yes & 5 & 16 & & \\
\hline No & 74 & 252 & & \\
\hline
\end{tabular}

Table 4 Univariate and multivariate analyses of the risk factors for poorly differentiated cancer in 347 cases of cervical cancer

\begin{tabular}{|c|c|c|c|c|c|c|}
\hline & \multicolumn{3}{|c|}{ Univariate analysis } & \multicolumn{3}{|c|}{ Multivariate analysis } \\
\hline & $\overline{\mathrm{HR}}$ & $95 \% \mathrm{Cl}$ & $P$ & $\overline{\mathrm{HR}}$ & $95 \% \mathrm{Cl}$ & $P$ \\
\hline $\begin{array}{l}\text { HPV58 } \\
\text { positivity }\end{array}$ & 3.652 & $1.060-12.584$ & 0.040 & 2.156 & $1.167-3.984$ & 0.014 \\
\hline $\begin{array}{l}\text { Age }<50 \\
\text { years old }\end{array}$ & 1.140 & $0.719-1.807$ & 0.578 & / & / & / \\
\hline SCC & 3.382 & $1.251-9.141$ & 0.016 & 3.677 & $1.335-10.130$ & 0.012 \\
\hline
\end{tabular}


Table 5 Univariate analysis of relationship of HPV genotypes and poorly differentiated cancer in cases with SCC

\begin{tabular}{llll}
\hline & HR & $95 \% \mathrm{Cl}$ & $\mathrm{P}$ \\
\hline HPV58 positivity & 7.038 & $1.067-46.437$ & $\mathbf{0 . 0 4 3}$ \\
HPV16 positivity & 0.335 & $0.109-1.152$ & 0.085
\end{tabular}

66.67 \pm 2.23 months, $P=0.000$ ) (Fig. 2a). There was no significant difference in overall survival between HPV16 positive cervical cancer patients with and without uterine corpus invasion $(51.54 \pm 2.59$ months vs $71.98 \pm$ 2.00months, $P=0.386$ ) (Fig. 2b).

\section{Binary logistic regression analysis for uterine corpus} invasion in patients with stage I-IIA cervical cancer Univariate analysis was performed on the factors affecting uterine corpus invasion to select the significant factors for the binary logistic regression model. HPV58 positivity was an independent risk factor for uterine corpus invasion $[\mathrm{HR}=3.985,95 \%$ confidence interval: 1.066-14.893, $P=0.040$ ] (Table 4). Besides , deep stromal invasion and LVSI show a HR of 2.039 [95\%CI:1.205-3.452, $P=0.008$ ] and 0.386 [95\%CI:0.1640.909, $P=0.029]$, respectively, which meant HPV58 positivity and deep stromal invasion were the risk factors for uterus corps invasion $(\mathrm{HR}>1)$ while LVSI not $(\mathrm{HR}<1)$ (Table 7$)$.
Analysis of stage IIB-IVB cervical cancer Clinical features of patients with stage IIB-IVB cervical cancer

A total of 158 patients with stage IIB-IVB cervical cancer did not receive surgery but received radiotherapy and chemotherapy. The age of the HPV58-positive cervical cancer group was significantly higher than that of the HPV16 positive cervical cancer group $(P=0.045)$. Other clinical features are not different from HPV16 positive cervical cancer cases (Table 8).

Comparison of overall survival in patients with stage IIB-IVB cervical cancer in different age groups

In spite of different HPV genotypes, the overall survival of patients with stage IIB-IVB cervical cancer in different age groups was not significantly different (56.42 \pm 4.38 months vs $45.66 \pm 3.20$ months, $P=0.760$ ) (Fig. 3). As to the overall survival of HPV58 positive cases, there was no significant difference between age $\leq 50$ and age $>50$ years old groups (50.48 \pm 4.15 months vs $47.09 \pm 3.56$ months, $P=0.893$ ) (Fig. 3a). Similarly, the overall survival of HPV16 positive cases was not significantly different between different age groups (56.67 \pm 10.59 months vs $44.90 \pm 5.19$ months, $P=0.735$ ) (Fig. 3b).

\section{Discussion}

The International Agency for Research on Cancer divided the HPV genotypes into the following groups

\section{Survival curve of HPV58 and HPV16 positive poorly differentiated cervical cancer cases}

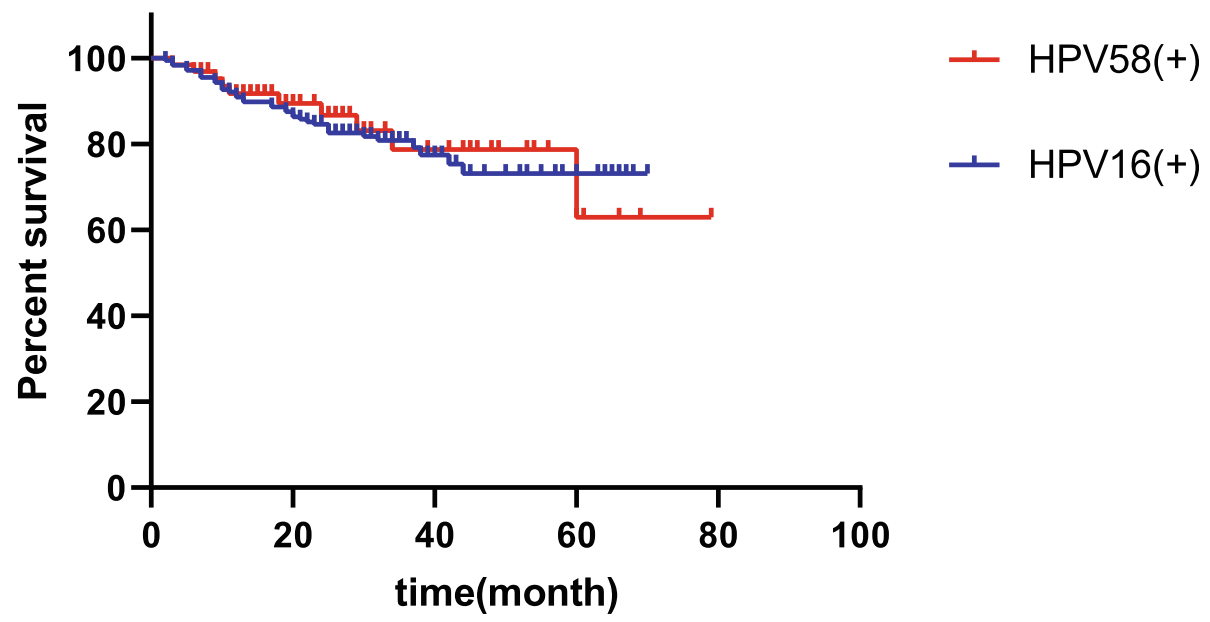

Fig. 1 survival curve of poorly differentiated cancer with HPV58 and HPV16 positive cervical cancer cases 
Table 6 The clinical feature of 189 cases of stage I- IIA patients with cervical cancer

\begin{tabular}{|c|c|c|c|c|}
\hline & HPV58 & HPV16 & $Z$ & $P$ \\
\hline$\overline{\text { Age }}$ & & & 0.107 & 0.744 \\
\hline$\leq 50$ years old & 18 & 76 & & \\
\hline$>50$ years old & 20 & 75 & & \\
\hline Pathology type & & & / & 1.000 \\
\hline SCC & 36 & 143 & & \\
\hline Non-SCC & 2 & 8 & & \\
\hline Differentiation & & & 2.980 & 0.084 \\
\hline Poor & 30 & 97 & & \\
\hline Moderately/well & 8 & 54 & & \\
\hline Maximum diameter & & & 1.114 & 0.291 \\
\hline$<4 \mathrm{~cm}$ & 21 & 69 & & \\
\hline$\geq 4 \mathrm{~cm}$ & 17 & 82 & & \\
\hline Depth of stromal invasion & & & 0.373 & 0.872 \\
\hline$<1 / 2$ & 14 & 62 & & \\
\hline $1 / 2 \sim 2 / 3$ & 7 & 28 & & \\
\hline$>2 / 3$ & 17 & 61 & & \\
\hline Lymph node metastasis & & & 0.371 & 0.543 \\
\hline Yes & 8 & 39 & & \\
\hline No & 30 & 112 & & \\
\hline LVSI & & & 0.106 & 0.745 \\
\hline Yes & 15 & 64 & & \\
\hline No & 23 & 87 & & \\
\hline Parametrial invasion & & & 0.988 & 0.320 \\
\hline Yes & 4 & 9 & & \\
\hline No & 34 & 142 & & \\
\hline Bladder invasion & & & / & 1.000 \\
\hline Yes & 1 & 4 & & \\
\hline No & 37 & 147 & & \\
\hline Rectal invasion & & & / & 0.492 \\
\hline Yes & 1 & 2 & & \\
\hline No & 37 & 149 & & \\
\hline Vaginal invasion & & & / & 0.125 \\
\hline Yes & 1 & 16 & & \\
\hline No & 37 & 135 & & \\
\hline Uterine corpus invasion & & & / & 0.041 \\
\hline Yes & 3 & 36 & & \\
\hline No & 35 & 115 & & \\
\hline Distant metastasis & & & / & 1.000 \\
\hline Yes & 0 & 1 & & \\
\hline No & 38 & 150 & & \\
\hline
\end{tabular}

according to their carcinogenesis: the highly carcinogenic Group 1 (HPV16, 18, 31, 33, 35, 39, 45, 51, 52, 56, 58 , and 59); the probably carcinogenic Group 2A (HPV
68); and the possibly carcinogenic Group 2B (HPV26, $30,34,53,66,67,69,70,73,82,85$, and 97) [10]. Both HPV58 and HPV16 belong to highly carcinogenic HPV, and they belong to $\alpha-9 \mathrm{HPV}$. HPV16 is more likely to cause cervical cancer [11]. In addition, HPV16 is the most common type of infection worldwide, comparing to HPV31, 33, 35 and 52 [9]. Therefore, this study compared HPV58 positive and HPV16 positive cervical cancer cases to demonstrate the clinical features of HPV58 positive cervical cancer.

Infection with different HPV subtypes may affect cervical cancer prognosis $[12,13]$, but there still be controversial. Because of the lack of study about HPV58 positive cervical cancer, the overall survival of HPV58 positive cervical cancer remains unclear. Hung-Cheng Lai et al. [12] reported that the prognosis of patients with HPV58-positive cervical cancer was better than that of patients with HPV16 positive cervical cancer. S. Y. Tong et al. [14] demonstrated that HPV genotypes had no effect on the prognosis of cervical cancer. ChyongHuey Lai et al. [15] revealed that HPV58/33/52 positivity was associated with early stage cervical cancer prognosis. Dong Hang et al. [13] suggested that $\alpha$-PV9 (including HPV16, 31, 33, 35, 52, 58 and 67) species-related cervical cancer had a better result than cervical cancers associated with other species of HPV. However, clinical stage plays a crucial role in prognosis, and the study did not divide data into different clinical stages. This study shows that there are some distinguishing features between HPV58-positive cervical cancer and HPV16 positive cervical cancer. The percentage of poorly differentiated cancer of HPV58 positive cervical cancer (79.75\%) is significantly higher than that of HPV16 (65.57\%), and HPV58 positive squamous cells carcinoma is vulnerable to poorly differentiated cancer. But the overall survival of poorly differentiated cancer cases is not significantly different between HPV58 positive and HPV16 positive groups. The result suggests that there are other factors relating to the prognosis of cervical cancer expect the discrepancies of HPV genotypes and pathology grades.

In this study, the proportion of uterine corpus invasion was significantly lower in the HPV58-positive cervical cancer group $(7.89 \%)$ than in the HPV16 positive group (31.30\%). Interestingly, however, multivariate analysis revealed that HPV58 positivity is an independent risk factor for uterine invasion in patients with stage I-IIA cervical cancer (HR 3.985). Meanwhile, deep stromal invasion is an independent risk factor for uterus corps invasion (HR 2.039). Only 3 cases of HPV58 positive stage IA-IIA cervical cancer occur uterus corps invasion, and the 3 cases are with deep stromal invasion $(\geq 2 / 3$ cervix stromal), implying that HPV58 positive cervical cancer in susceptible to uterus corps invasion. But more 


\section{Survival curve of stage IA-IIA cervical cancer cases with or without uterus corps invasion}

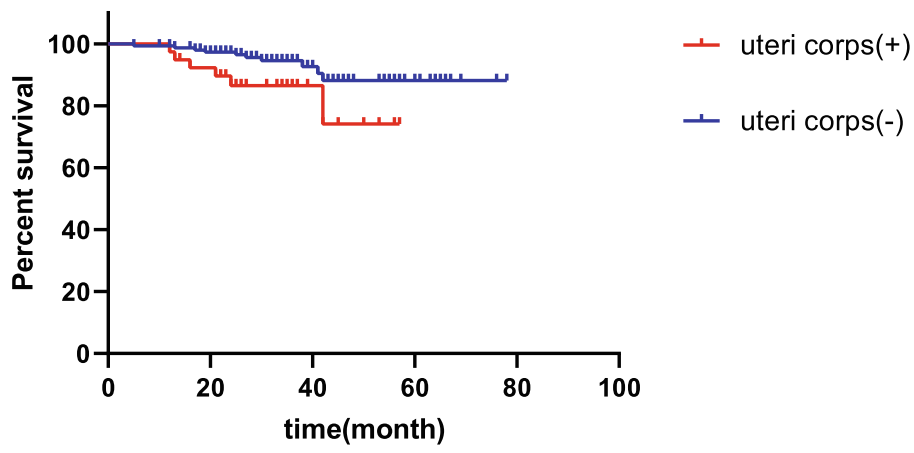

A

Survival curve of HPV58 positive cervical cancer cases with or without uterus corps invasion

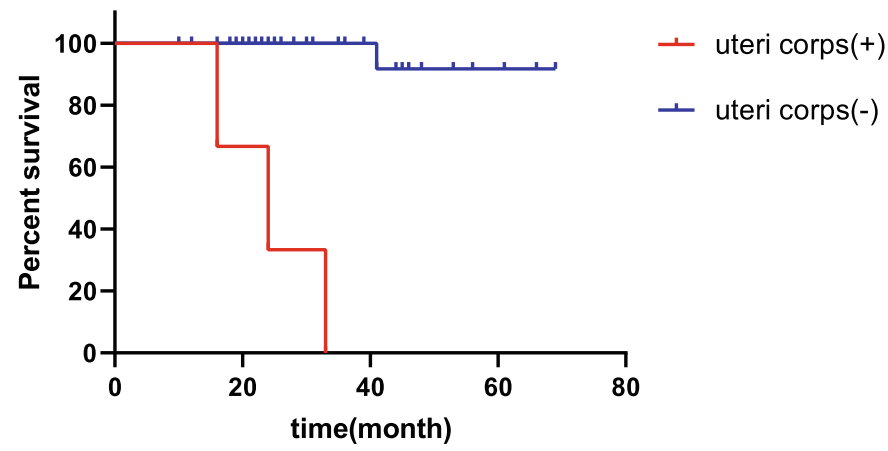

B

\section{Survival curve of HPV16 positive cervical cancer cases with or without uterus corps invasion}

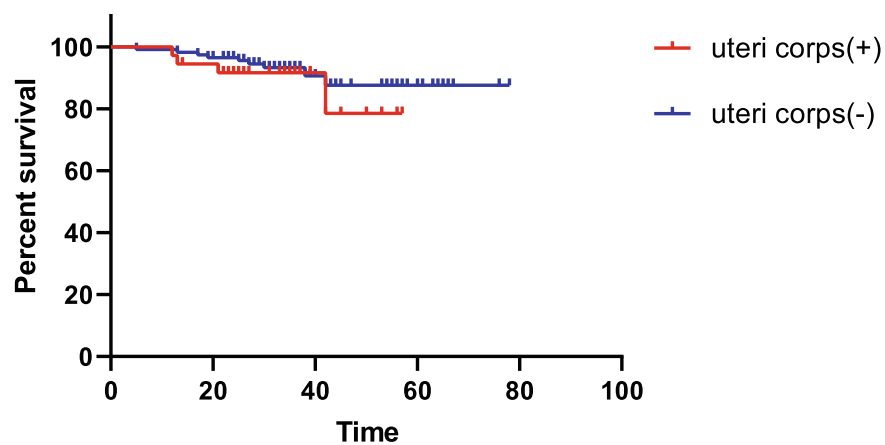

Fig. 2 survival curve of stage IA-IIA cervical cancer cases with or without uterus corps invasion. a: survival curve of HPV58 positive stage IA-IIA cervical with or without uterus corps invasion. b: survival curve of HPV16 positive stage IA-IIA cervical with or without uterus corps invasion

cases should be included further to confirm that. In addition, all these 3 cases have LVSI, which is consistent with the result of multivariable analysis that LVSI is not the risk factor of uterus corps invasion (HR 0.386). The result is coincident with previous researches. Chen et al [5] pointed out that HPV58 positive cervical cancer was more susceptible to LVSI than HPV16 positive cases, however whether LVSI acted as the risk factor for remain to ambiguous. K. Matsuo and his colleagues [16] reported that older age, larger tumor diameter, poor differentiation, nonsquamous cell carcinoma and lymph node metastasis were risk factors for uterine corpus invasion in early-stage cervical cancer, and uterine body invasion was an independent risk factor for poor 
Table 7 Univariate and multivariate analyses of the risk factors for uterine corpus invasion in stage I-IIA cervical cancer

\begin{tabular}{|c|c|c|c|c|c|c|}
\hline & Univa & & & Multiv & ysis & \\
\hline & $\overline{\mathrm{HR}}$ & $95 \% \mathrm{Cl}$ & $\mathrm{P}$ & $\overline{\mathrm{HR}}$ & $95 \% \mathrm{Cl}$ & $P$ \\
\hline HPV58 positivity & 3.652 & $1.060-12.584$ & 0.040 & 3.985 & $1.066-14.893$ & 0.040 \\
\hline Age $<50$ years old & 1.365 & $0.672-2.774$ & 0.390 & / & / & / \\
\hline Non-SCC & 2.426 & $0.298-19.744$ & 0.408 & / & / & / \\
\hline Moderately/well differentiated & 0.484 & $0.235-0.996$ & 0.049 & 0.531 & $0.239-1.180$ & 0.120 \\
\hline Maximum diameter $>4 \mathrm{~cm}$ & 1.834 & $0.885-3.799$ & 0.103 & / & / & / \\
\hline Depth of stromal invasion & 2.494 & $1.569-3.965$ & 0.000 & 2.039 & $1.205-3.452$ & 0.008 \\
\hline Lymph node metastasis (+) & 0.280 & $0.132-0.591$ & 0.000 & 0.636 & $0.266-1.521$ & 0.309 \\
\hline LVSI (+) & 0.236 & $0.110-0.504$ & 0.000 & 0.386 & $0.164-0.909$ & 0.029 \\
\hline Parametrial invasion (+) & 0.383 & $0.118-1.245$ & 0.111 & / & / & / \\
\hline Bladder invasion (+) & 0.162 & $0.026-1.007$ & 0.051 & / & / & / \\
\hline Rectal invasion (+) & 0.514 & $0.045-5.814$ & 0.590 & / & / & / \\
\hline Vaginal invasion (+) & 0.327 & $0.115-0.923$ & 0.035 & 0.523 & $0.166-1.645$ & 0.267 \\
\hline
\end{tabular}

Table 8 Clinical features of 158 patients with advanced stage cervical cancer

\begin{tabular}{|c|c|c|c|c|}
\hline & HPV58 & HPV16 & Z & $\mathrm{P}$ \\
\hline$\overline{\text { Age }}$ & & & 4.034 & 0.045 \\
\hline$\leq 50$ years old & 9 & 46 & & \\
\hline$>50$ years old & 32 & 71 & & \\
\hline Differentiation & & & 3.657 & 0.056 \\
\hline Poorly & 32 & 77 & & \\
\hline Moderately/well & 6 & 36 & & \\
\hline Maximum diameter & & & 0.152 & 0.696 \\
\hline$<4 \mathrm{~cm}$ & 7 & 17 & & \\
\hline$\geq 4 \mathrm{~cm}$ & 34 & 100 & & \\
\hline Lymph node metastasis & & & 0.076 & 0.783 \\
\hline Yes & 20 & 57 & & \\
\hline No & 21 & 60 & & \\
\hline Bladder invasion & & & 0.682 & 0.409 \\
\hline Yes & 6 & 24 & & \\
\hline No & 35 & 93 & & \\
\hline Rectal invasion & & & / & 0.104 \\
\hline Yes & 2 & 18 & & \\
\hline No & 39 & 99 & & \\
\hline Vaginal invasion & & & 0.286 & 0.593 \\
\hline Yes & 24 & 74 & & \\
\hline No & 17 & 43 & & \\
\hline Uterine corpus invasion & & & 0.351 & 0.553 \\
\hline Yes & 19 & 48 & & \\
\hline No & 22 & 69 & & \\
\hline Distant metastasis & & & 0.011 & 0.917 \\
\hline Yes & 5 & 15 & & \\
\hline No & 36 & 102 & & \\
\hline
\end{tabular}

prognosis in early cervical cancer. Similarly, Mihai Meirovitz et al. [17] noted that tumor diameter over $2 \mathrm{~cm}$, deep interstitial infiltration (over $5 \mathrm{~mm}$ ) and lymphovascular space invasion were independent risk factors for extracervical involvement. These results are somewhat similar to those of this study. But it is difficult to speculate whether HPV genotype is a risk factor for uterine corpus invasion because of the lack of studies on the involvement of HPV genotype. According to the results of this study, there are more cases of poorly differentiated cancer in the HPV58 positive cervical cancer group than in the HPV16 positive group. HPV58 is likely associated with poorly differentiated cancer, which makes the tumor more prone to deep stromal invasion. However, further experimental studies are needed. Therefore, for patients with HPV58 positive stage IA-IIA cervical squamous cells carcinoma, who are diagnosed with poorly differentiated cancer and deep stromal invasion, it is necessary to be aware of the possibility of uterine corps invasion.

Despite the HPV genotypes, the overall survival of patients with uterine corpus invasion is significantly shorter than that of patients without uterine corpus invasion (49.27 \pm 2.72 months vs $72.46 \pm 1.78$ months, $P=0.041$ ). Although HPV58-positive cervical cancer is less likely to have uterine corpus invasion, the prognosis of HPV58positive cervical cancer with uterine corpus invasion is worse than that of without uterine corpus invasion (24.33 months vs $66.67 \pm 2.23$ months, $P=0.000$ ). But it is no significant difference between HPV16 positive cervical cancer cases with or without uterus corps invasion (51.54 \pm 2.59 months vs $71.98 \pm 2.00$ months, $P=0.386$ ). According to previous multivariable analysis that shows HPV58 positivity is associated to uterus corps invasion (HR 3.985), it is speculated that HPV genotype is correlated to prognosis 


\section{Survival curve of stage IIB-IVB cervical cancer cases} in different age groups

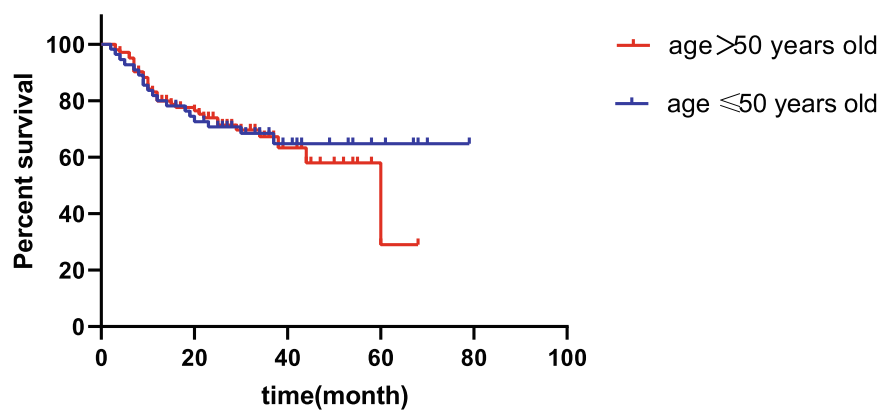

A

Survival curve of HPV58 positive cervical cancer cases in different age groups
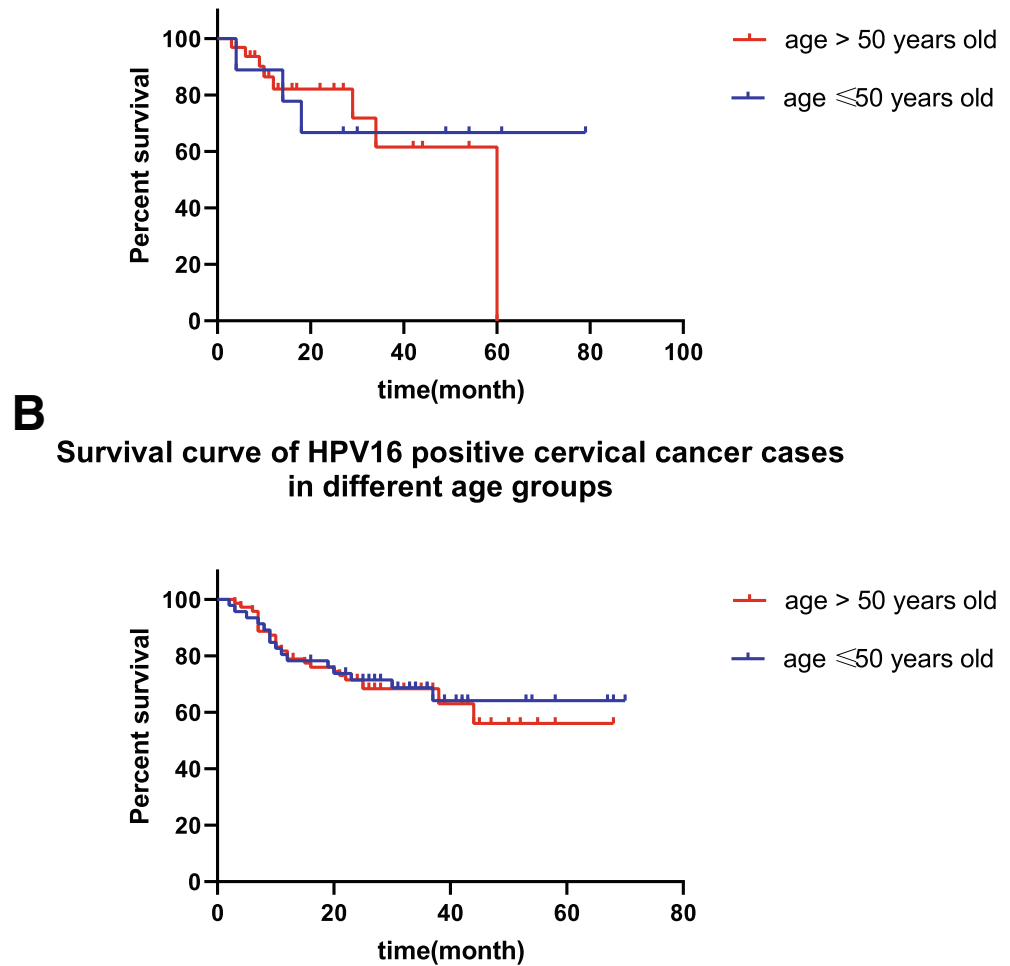

Fig. 3 survival curve of stage IIB-IVB cervical cancer cases in different age groups stage. a: survival curve of HPV58 positive stage IIB-IVB cervical cancer cases in different age groups stage. $\mathbf{b}$. survival curve of HPV16 positive stage IIB-IVB cervical cancer cases in different age groups stage

of cervical cancer with uterus corps invasion. Uterine corpus invasion is not part of the 2018 FIGO staging system, or the 2019 NCCN guidelines which has been updated recently. The average survival time of patients with uterine corpus invasion and early cervical cancer is 11.2 years, which is significantly lower than that of patients with early cervical cancer but without uterine corpus invasion (14.2 years) [16]. Uterine corpus invasion in early-stage cervical cancer suggests that the tumor is more aggressive [18]. In this study, the 3 cases of HPV58 positive cervical cancer with uterus corps invasion occur deep stromal invasion, which verify the aggression of cervical cancer with uterus corps invasion.

There are a total of 159 cases of stage IIB-IVB cervical cancer. In cases of stage IIB-IVB cervical cancer, the proportion of patients with HPV58-positive cervical cancer over 50 years is significantly higher than that of patients with HPV16 positive cervical cancer. Likely, Hung-Cheng LAI at el [12] got the same result that the age of HPV58 positive cervical cancer patients were older than that of HPV16 positive cases. But the difference of age do not show in the cases of stage IA-IIA. It 
suggests that HPV58 positive cervical cancer advance more slowly than HPV16 positive and costs more time to advanced stage, which may explain that the patients with HPV58 stage IIB-IVB cervical cancer are older. However, the overall survival of different age groups of stage IIB-IVB cases is not significantly different. Further analysis of HPV58 and HPV16 positive cervical cancer was performed respectively, the similar results were obtained. Although Quinn at el [19]. revealed that the older age is responsible for worse prognosis of cervical cancer patients, it is HR of 1.46 in the age groups of 5069 years old while that is 2.87 in the age of over 70 years old. The research did not stratify the HPV genotypes, while different HPV genotypes affect the prognosis to some extent, such as HPV18 positive cervical cancer is related to unsatisfied outcome [13], these factors might have effects on the research. Comparing Quinn's research, our study just includes HPV58 and HPV16 positive cases, which may interpret the inconsistent results.

There are still some limitations in this study. First, this is a single-center retrospective analysis with a small sample size. Second, the disease-free survival data are incomplete and were not included in the results of this study. The assessment of recurrence could not be performed.

\section{Conclusion}

In conclusion, regardless of clinical stage, HPV58-positive cervical cancer patients are at higher risk of poorly differentiated cancer, but it is no related to the prognosis. Although the patients with early stage HPV58-positive cervical cancer are not easy to occur uterus corps invasion, the prognosis is worse than that without uterus corps invasion. As to the HPV58 positive early stage cervical squamous cells carcinoma patients who are diagnosed with poorly differentiated cancer and deep stromal invasion should be vigilant to uterus corps invasion. And advanced-stage HPV58-positive cervical cancer is more common in patients over 50 years old than in patients 50 years or younger.

\section{Acknowledgements}

We are thankful to the American Journal Experts for English language editing.

\section{Acknowledgements of research support}

This study is supported by the National Public Welfare Research Project (no. 201402010), the Thousand-Hundred-Ten Talent Project of Guangxi Province (no. 2015226) and the 139 Medical High-level Talents Training Plan of Guangxi Province.

\section{Authors' contributions}

Li Li acted as the guarantor of this study and conceived the idea. Mengjie Chen and He Wang collected the data and wrote this paper. Mengjie Chen performed statistical analysis. And Yuejuan Liang performed manuscript editing. The authors read and approved the final manuscript.

\section{Funding}

This study was supported by the National Public Welfare Research Projects (NO. 201402010), the Thousand-Hundred-Ten Talent Project of Guangxi Province (NO.2015226) and the 139 Medical High-level Talents Training Plan of Guangxi Province.

\section{Availability of data and materials}

The datasets used and/or analyzed during the current study are available from the corresponding author on reasonable request.

\section{Ethics approval and consent to participate}

This study was approval by the Institutional Ethics Committee of Guangxi Medical University affiliated Cancer Hospital. Informed consent was obtained from the studied patients.

\section{Consent for publication}

Informed consent was obtained from all individual participants included in the study.

\section{Competing interests}

No potential conflict of interest relevant to this article was reported.

Received: 27 January 2020 Accepted: 14 May 2020

Published online: 05 June 2020

References

1. Chen W, Zheng R, Baade PD, Zhang S, Zeng H, Bray F, et al. Cancer statistics in China, 2015. CA Cancer J Clin. 2016:66:115-32.

2. Ho GY, Burk RD, Klein S, Kadish AS, Chang CJ, Palan P, et al. Persistent genital human papillomavirus infection as a risk factor for persistent cervical dysplasia. J Natl Cancer Inst. 1995;87:1365-71.

3. Li N, Franceschi S, Howell-Jones R, Snijders PJ, Clifford GM. Human papillomavirus type distribution in 30,848 invasive cervical cancers worldwide: variation by geographical region, histological type and year of publication. Int J Cancer. 2011;128:927-35

4. Long W, Yang Z, Li X, Chen M, Liu J, Zhang Y, et al. HPV-16, HPV-58, and HPV-33 are the most carcinogenic HPV genotypes in southwestern China and their viral loads are associated with severity of premalignant lesions in the cervix. Virol J. 2018;15:94.

5. Chen Z, Zhou J, Chen Y, Zhu J. Distribution of human papillomavirus genotypes and its relationship to clinicopathology in invasive cervical carcinoma in Zhejiang Province, China. J Cancer Res Ther. 2018;14:780-4.

6. Wang $H$, Cheng $X, Y e J, X u X$, Hong Y, Sui L, et al. Distribution of human papilloma virus genotype prevalence in invasive cervical carcinomas and precancerous lesions in the Yangtze River Delta area, China. BMC Cancer. 2018;18:487

7. Okonogi N, Kobayashi D, Suga T, Imai T, Wakatsuki M, Ohno T, et al. Human papillomavirus genotype affects metastatic rate following radiotherapy in patients with uterine cervical cancer. Oncol Lett. 2018;15:459-66.

8. Chan PK, Ho WC, Chan MC, Wong MC, Yeung AC, Chor JS, et al. Metaanalysis on prevalence and attribution of human papillomavirus types 52 and 58 in cervical neoplasia worldwide. PLoS One. 2014:9:e107573.

9. de Sanjose S, Quint WG, Alemany L, Geraets DT, Klaustermeier JE, Lloveras B, et al. Human papillomavirus genotype attribution in invasive cervical cancer: a retrospective cross-sectional worldwide study. Lancet Oncol. 2010;11: $1048-56$.

10. Bzhalava D, Guan P, Franceschi S, Dillner J, Clifford G. A systematic review of the prevalence of mucosal and cutaneous human papillomavirus types. Virology. 2013;445:224-31.

11. Li K, Yin R, Wang D, Li Q. Human papillomavirus subtypes distribution among 2309 cervical cancer patients in West China. Oncotarget. 2017;8: 28502-9.

12. Lai HC, Sun CA, Yu MH, Chen HJ, Liu HS, Chu TY. Favorable clinical outcome of cervical cancers infected with human papilloma virus type 58 and related types. Int J Cancer. 1999:84:553-7.

13. Hang D, Jia M, Ma H, Zhou J, Feng X, Lyu Z, et al. Independent prognostic role of human papillomavirus genotype in cervical cancer. BMC Infect Dis. 2017;17:391

14. Onuki M, Matsumoto K, Tenjimbayashi Y, Tasaka N, Akiyama A, Sakurai M, et al. Human papillomavirus genotype and prognosis of cervical cancer: 
favorable survival of patients with HPV16-positive tumors. Papillomavirus research (Amsterdam, Netherlands). 2018;6:41-5.

15. Lai CH, Chang CJ, Huang HJ, Hsueh S, Chao A, Yang JE, et al. Role of human papillomavirus genotype in prognosis of early-stage cervical cancer undergoing primary surgery. JClin Oncol. 2007;25:3628-34.

16. Matsuo K, Machida H, Blake EA, Takiuchi T, Mikami M, Roman LD.

Significance of uterine corpus tumor invasion in early-stage cervical cancer. Eur J Surg Oncol. 2017;43:725-34.

17. Meirovitz M, Sade S, Dreiher J, Shaco-Levy R. Is radical hysterectomy necessary in early cervical cancer? Gynecol Obstet Investig. 2013;76:158-62.

18. Narayan K, Fisher RJ, Bernshaw D. Patterns of failure and prognostic factor analyses in locally advanced cervical cancer patients staged by magnetic resonance imaging and treated with curative intent. Int J Gynecol Cancer. 2008;18:525-33.

19. Quinn BA, Deng X, Colton A, Bandyopadhyay D, Carter JS, Fields EC Increasing age predicts poor cervical cancer prognosis with subsequent effect on treatment and overall survival. Brachytherapy. 2019;18:29-37.

\section{Publisher's Note}

Springer Nature remains neutral with regard to jurisdictional claims in published maps and institutional affiliations.

Ready to submit your research? Choose BMC and benefit from:

- fast, convenient online submission

- thorough peer review by experienced researchers in your field

- rapid publication on acceptance

- support for research data, including large and complex data types

- gold Open Access which fosters wider collaboration and increased citations

- maximum visibility for your research: over $100 \mathrm{M}$ website views per year

At $\mathrm{BMC}$, research is always in progress.

Learn more biomedcentral.com/submissions 